\title{
WELFARE OPTIMIZATION AND MULTINATIONAL MONOPOLIES
}

\author{
A. M. RUSSELL ${ }^{1}$, C. A. MARTINI ${ }^{2}$ and J. A. RICKARD ${ }^{3}$
}

(Received 9 November 1993; revised 14 February 1995)

\begin{abstract}
This paper examines the role of import tariffs and consumption taxes when a product is supplied to a domestic market by a foreign monopoly via a subsidiary. It is assumed that there is no competition in the domestic market from internal suppliers. The home country is able to levy a profits tax on the subsidiary. The objective of our analysis is to determine the mix of tariff and consumption tax which simultaneously maximizes national welfare. We show that national welfare does not have an internal maximum, but attains its maximum on a boundary of the consumption tax-tariff parameter space. Furthermore, the optimal value of national welfare increases as the tariff decreases and the consumption tax increases. The results obtained generalize the results of an earlier paper in which national welfare was maximized with respect to either a tariff or consumption tax, but not both.
\end{abstract}

\section{Introduction}

In an earlier paper, Rickard, Russell and Martini [14] examined the roles of import tariffs and consumption taxes when a product is supplied to a domestic market by a foreign monopoly via a subsidiary. It was assumed that there was no competition in the domestic market from internal suppliers and that the home country was able to levy a profits tax on the subsidiary. The major policy implication of the analysis is that a consumption tax is the more effective instrument for maximizing national welfare provided the profits tax is less than a certain critical value; if the profits tax exceeds this value, then a tariff, though in the form of a subsidy, is the more effective instrument. The nature of the optimal taxes and whether in fact the optimum is a tariff or a subsidy varies according to whether it is a specific or an ad valorem tax that is being considered. In Katrak's model [8] and the refinement in [14] the tariff is

\footnotetext{
'Faculty of Business and Economics, Monash University, and Dept. of Maths, University of Melbourne, Australia.

${ }^{2}$ Department of Accounting and Finance, University of Melboume, Australia.

${ }^{3}$ Faculty of Business and Economics, Monash University, Australia.

(C) Australian Mathematical Society, 1996, Serial-fee code 0334-2700/96
} 
specific, while the consumption tax is ad valorem. With no profits tax and assuming that any industry is small relative to the whole economy, Brander and Spencer [1] consider the imposition of specific and ad valorem tariffs in the context of a foreign monopoly cartel. Assuming constant marginal cost they find that with a specific tariff regime, whether a subsidy is optimal depends on the convexity of demand.

While Brander and Spencer [1], [2] demonstrate that the effectiveness of each tax is sensitive to the curvature of the demand curve, they do not directly compare the levels of cost and welfare attainable under each of the different tax regimes, and furthermore their analysis, surprisingly, does not include any consideration of a profits tax. In a footnote in [1], it is pointed out that comparisons of welfare are possible in special cases, but are difficult in a general setting which they adopt. However, in [14], direct comparisons of costs and welfare are compared under the optimal choice of either a specific tariff or an ad valorem consumption tax when a product is supplied to a domestic market by a foreign monopoly via a subsidiary, assuming only a linear demand curve, and it is shown that costs and welfare levels are dependent on the profits tax and also the slope of the demand curve.

When markets are imperfectly competitive and existing firms can earn pure profits, then policy intervention may be justified and domestic welfare can be increased with appropriate use of tariffs or subsidies. This raises the question as to whether some mix of the two taxes would be more beneficial than application of either tax separately. Consequently, in this paper the same model as in [14] is adopted, but the analysis is no longer restricted to apply to the application of either a consumption tax or a tariff. Instead, the welfare function becomes a function of the two variables, consumption tax and tariff, and the mix which simultaneously optimises national welfare is sought. It is confirmed, as Brander and Spencer [1] point out, that a strategy which allows a combination of a specific and an ad valorem tax to be applied will weakly dominate either pure regime.

In this paper it is shown, in particular, that although national welfare can be arbitarily large and negative it has a positive global upper bound. The maximum positive value of national welfare occurs on a boundary of the consumption tax-tariff parameter space and the optimal value increases as the tariff decreases and the consumption tax increases. The tariff may in fact be a subsidy. Moreover, if the government chooses that value of consumption tax that maximizes welfare under a pure consumption tax regime, for a given profits tax, then the welfare optimizing tariff will always be a subsidy, and furthermore the corresponding level of welfare will be higher. A simple qualitative argument to support these results is now presented, and the subsequent analysis will confirm them. The authors are grateful to an unknown referee for the following argument.

For any rate of tariff $t$ (which shifts the marginal cost curve from $C_{m}$ to $(1+t) C_{m}$ and reduces output from $q_{0}$ to $q_{t}$ ), there is a rate of consumption tax $c$ which raises 


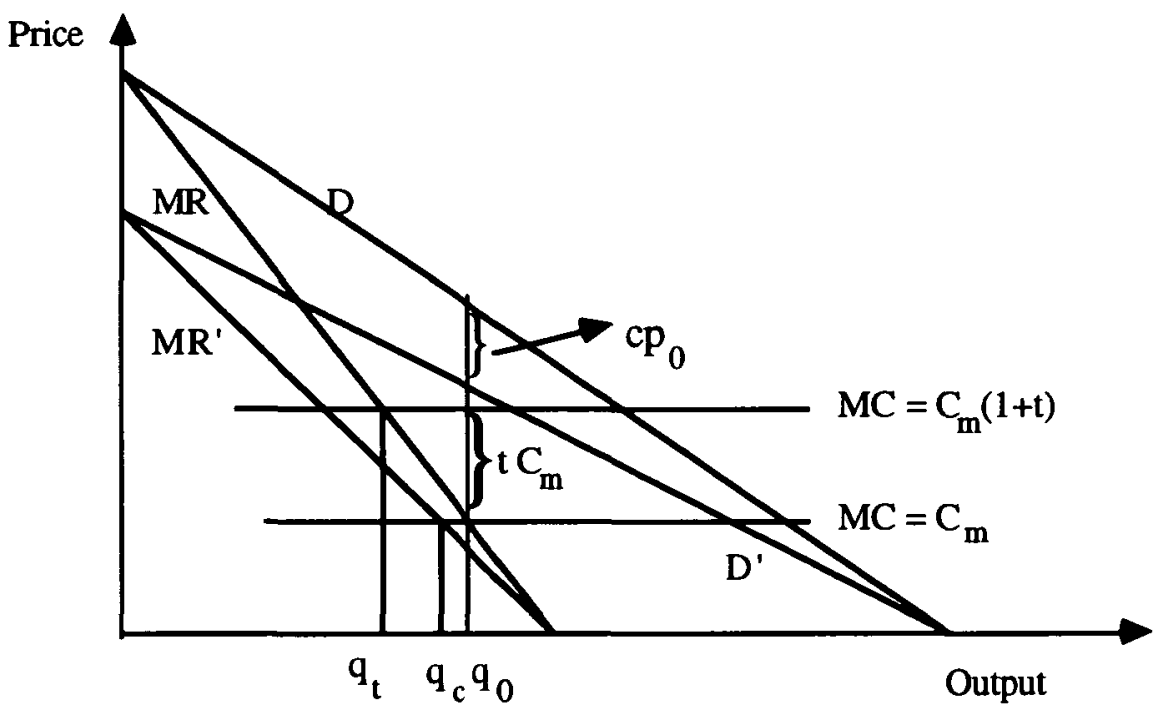

Figure 1.

the same per unit tax at $q_{0}$ (that is, $t C_{m}=c p_{0}$ ). It is easy to see from Figure 1 that the consumption tax shifts the demand curve from $D$ to $D^{\prime}$, making it flatter. Hence the new equilibrium output under the consumption tax alternative $q_{c}$ must be greater than $q_{t}$. Thus consumer price must be lower and, at least when demand is elastic, consumption tax revenue must be higher, all pointing to higher welfare and the inferiority of a tariff compared to a consumption tax. This strongly suggests that with a mix of tariff and consumption tax, a negative tariff and a high consumption tax will optimize welfare. The subsequent analysis confirms this conjecture.

\section{The model}

Assume a linear demand function given by

$$
q=\alpha-\beta p(1+c),
$$

where $q$ denotes the quantity in demand, $p$ is the price level (per unit) set by the firm, $\alpha$ and $\beta$ are positive constants, and the consumption tax is $100 c \%$ of the price to the firm. Note that $p(1+c)$ is the price paid by the consumers.

Let $C_{m}$ denote the constant carriage, insurance and freight (c.i.f.) marginal cost, and let the rate of import tariff or subsidy, expressed as a proportion of $C_{m}$, be denoted by $t$; so $t>0$ denotes a tariff, and $t<0$ denotes a subsidy. The corresponding profit for the importing firm is given by

$$
\pi=p q-C_{m}(1+t) q,
$$


which on substituting for $p$ in terms of $q$ from (1) becomes

$$
\pi=\frac{q(\alpha-q)}{\beta(1+c)}-C_{m}(1+t) q,
$$

provided of course that $1+c \neq 0$, that is, $c \neq-1$. The condition $c \leq-1$ gives rise to an abnormal demand function, and consequently we assume henceforth that $1+c>0$.

Assume now that the firm exercises profit maximization. It then follows immediately from (3) that profit maximization occurs when demand $\bar{q}$ is given by

$$
\bar{q}=\left\{\alpha-\beta C_{m}(1+c)(1+t)\right\} / 2,
$$

and the corresponding price $\bar{p}$ is given by

$$
\bar{p}=\frac{\alpha-\bar{q}}{\beta(1+c)}=\frac{1}{2 \beta(1+c)}\left[\alpha+\beta C_{m}(1+c)(1+t)\right] .
$$

To ensure that $\bar{q}$ is positive, it follows from (4) that the condition

$$
\alpha \geq \beta C_{m}(1+c)(1+t)
$$

must be satisfied, together with the restriction $c>-1$.

The optimal profit is consequently given by

$$
\begin{aligned}
\bar{\pi} & =\bar{p} \bar{q}-C_{m}(1+t) \bar{q} \\
& =\frac{(\alpha-\bar{q}) \bar{q}}{\beta(1+c)}-C_{m}(1+t) \bar{q} \\
& =\frac{(\alpha-\bar{q}) \bar{q}-\beta C_{m}(1+c)(1+t) \bar{q}}{\beta(1+c)} \\
& =\frac{\bar{q}^{2}}{\beta(1+c)},
\end{aligned}
$$

which is always positive since $1+c>0$.

Welfare in the home country can be increased by some suitable choice of consumption tax and tariff. Therefore the mix $(c, t)$ is sought that will maximize the sum of tariff revenue, profit tax revenue, consumption tax revenue and consumer surplus. The welfare function $W$ is given by

$$
W(c, t)=C_{m} t \bar{q}+r \bar{\pi}+c \bar{p} \bar{q}+\int_{0}^{\bar{q}}(1+c)(p-\bar{p}) d q,
$$

where the tax rate on profits is denoted by $100 r \%$, so that $0 \leq r \leq 1$. Observe that the right-hand side of (7) is a function of the three parameters $c, t$ and $r$, and is in 
particular a strictly increasing function of $r$. Assume that the government fixes the profits tax rate as, for example, in Australia where the company tax rate is constant. Then the welfare function can be regarded as being a function of just two variables $c$ and $t$, and optimized accordingly for a fixed value of $r$.

Note also that (7) is expressed in terms of efficiency to the complete exclusion of distributional considerations. This approach in treating a dollar as a dollar, separating efficiency and equality issues, can be justified using the same argument that $\mathrm{Ng}$ adopts in Section 3 of [14]. In that paper $\mathrm{Ng}$ points out that the usual objection to the principle of "a dollar is a dollar" is the question of inequality in income distribution, since a dollar to the poor is generally more important than a dollar to the rich, and hence that the benefits or costs should be valued accordingly in the application of a welfare function. However, $\mathrm{Ng}$ proceeds to show that income equality is better achieved by means of income tax, thus justifying our approach.

It follows from (7), after expressing $\bar{p}$ in terms of $\bar{q}$, that

$$
W(c, t)=C_{m} t \bar{q}+\frac{r}{\beta(1+c)} \bar{q}^{2}-\bar{p} \bar{q}+\frac{1}{\beta} \int_{0}^{\bar{q}}(\alpha-\bar{q}) d q,
$$

which reduces to

$$
\begin{aligned}
W(c, t)= & {\left[C_{m} t+\frac{\alpha}{\beta}-\frac{\alpha}{\beta(1+c)}\right] \bar{q}+\left[\frac{1+r}{\beta(1+c)}-\frac{1}{2 \beta}\right] \bar{q}^{2} } \\
= & \frac{1}{2}\left[\alpha-\beta C_{m}(1+c)(1+t)\right]\left[C_{m} t+\frac{\alpha}{\beta}-\frac{\alpha}{\beta(1+c)}\right] \\
& +\frac{1}{4}\left[\alpha-\beta C_{m}(1+c)(1+t)\right]^{2}\left[\frac{1+r}{\beta(1+c)}-\frac{1}{2 \beta}\right] .
\end{aligned}
$$

\section{Analysis of the model}

Before proceeding with an analysis of $W(c, t)$, it is convenient to make some changes of variables, by putting $x=1+c, y=1+t$ and $k=\alpha /\left(\beta C_{m}\right)$, so that $x>0$. With this new notation, (8) can be written as

$$
\begin{aligned}
\mathbf{W} \equiv \mathbf{W}(c, t) & =4 W(c, t) /\left(\beta C_{m}^{2}\right) \\
& =2(k-x y)\left[y-1+k-\frac{k}{x}\right]+(k-x y)^{2}\left(\frac{1+r}{x}-\frac{1}{2}\right) .
\end{aligned}
$$

Further manipulation of the right-hand side of (9) enables $\mathbf{W}$ to be written in the form

$$
\mathbf{W}=2(k-1)^{2}-\frac{1}{2}(x y+k-2)^{2}-\left(\frac{1-r}{x}\right)(x y-k)^{2} .
$$


Subsequent analysis of $\mathbf{W}$ will of course be undertaken subject to the earlier constraints, $x>0$ and $x y \leq k$. The following important result is now established.

THEOREM 1. The national welfare function has a positive global upper bound. More precisely,

$$
W(c, t) \leq\left(\alpha-\beta C_{m}\right)^{2} /(2 \beta)
$$

for all values of $c(>-1), t$ and $r$.

PROOF. The result follows immediately from (10).

REMARK 1. In Theorem 1 , it is shown that $2(k-1)^{2}$ is an upper bound for $\mathbf{W}$, as distinct from being the maximum value for $\mathbf{W}$. If $0 \leq r<1$, the value $2(k-1)^{2}$ can never be actually attained by $\mathbf{W}$ except in the special case when $k=1$, for then the two terms $(x y+k-2)$ and $(x y-k)$ can be zero simultaneously. However, the case $k=1$ is of little interest because the maximum value of $\mathbf{W}$ is zero.

REMARK 2. Clearly, maximum welfare must be at least as great as that achieved separately under either a consumption tax or a tariff, as analysed in [14]; in fact, there it was shown that

$$
\lim _{r \rightarrow 1-} W_{c^{*}}=\alpha\left(3 \alpha-4 \beta C_{m}\right) /(8 \beta),
$$

which is equal to $W(c, t, r)$ when $t=-1$ and $r=1$, irrespective of the value of $c$. Furthermore,

$$
W(c,-1, r) \rightarrow \alpha\left(3 \alpha-4 \beta C_{m}\right) /(8 \beta) \quad \text { as } c \rightarrow \infty \text {. }
$$

Theorem 2 summarizes these results.

THEOREM 2.

$$
\max \left[W_{c^{*}}, W_{t^{*}}\right] \leq \max _{(c, t)} W(c, t) \leq 2(k-1)^{2} .
$$

Theorem 3 shows that the maximum value of national welfare occurs on a boundary in $(c, t)$ parameter space.

THEOREM 3. The national welfare function $W(c, t)$ does not have an interior maximum for $0 \leq r<1$. 
PROOF. The first order conditions for maximizing $\mathbf{W}$ are

$$
\frac{\partial \mathbf{W}}{\partial x}=-(x y+k-2) y+\left(\frac{1-r}{x^{2}}\right)(x y-k)^{2}-\frac{2 y}{x}(1-r)(x y-k)=0
$$

and

$$
\frac{\partial \mathbf{W}}{\partial y}=-(x y+k-2) x-2(1-r)(x y-k)=0 .
$$

It follows from (12) that $x y+k-2=\frac{2}{x}(1-r)(k-x y)$, which upon substitution in (11) gives, after simplification, $\left(\frac{1-r}{x^{2}}\right)(x y-k)^{2}=0$, which can only be satisfied if $r=1$ or $x y=k$. However, if $r \neq 1$ then $x y=k$, and (11) becomes $(x y+k-2) y=0$, while (12) becomes $(x y+k-2) x=0$. Since $x>0$, the condition, $x y+k-2=0$, must hold, which is a contradiction unless $k=1$, a case which was dismissed earlier.

REMARK. When $r=1$ it follows from (10) that

$$
\mathbf{W}=2(k-1)^{2}-(x y+k-2)^{2} / 2,
$$

and this will have a maximum value of $2(k-1)^{2}$ when $x y=2-k$.

The case $r=1$ is clearly exceptional and of lesser interest from a practical point of view, so it will often be omitted from subsequent discussion.

\section{Optimal value of the welfare function}

It is clear from the previous theorem that $\mathbf{W}$ does not have an interior maximum in general. In order to examine the welfare surface it is instructive in the first instance, to examine the contour $\mathbf{W}=0$. In order to do this return to (9), and after some rearrangement, write $\mathbf{W}$ in the form

$$
\mathbf{W}=\left[\frac{k-x y}{x}\right]\left(1-r+\frac{1}{2}\right)\left[x y-\frac{2 k(1-r)+x(4-3 k)}{2(1-r)+x}\right] .
$$

Features of the welfare surface are now examined more precisely, and optimal boundary values of the welfare function are determined.

First consider the maximum values of $\mathbf{W}$ along the contours $x=$ constant, that is, hold the consumption tax constant. It follows from (12) and the sign of $\partial^{2} \mathbf{W} / \partial y^{2}$, that along these contours, $W$ attains its maximum value when

$$
x y+k-2=\frac{2}{x}(1-r)(k-x y),
$$


which after some rearrangement, can be written as

$$
y=\frac{2 k(1-r)+x(2-k)}{x^{2}+2 x(1-r)} .
$$

It now readily follows that

$$
x y+k-2=\frac{4(1-r)(k-1)}{x+2(1-r)}
$$

and

$$
x y-k=\frac{2 x(1-k)}{x+2(1-r)} .
$$

Consequently, substituting (14) and (15) into (10) and simplifying gives the optimum value of $\mathbf{W}$, for a given $x$, as

$$
\max _{y} \mathbf{W}=2(k-1)^{2}\left[1-\frac{2(1-r)}{x+2(1-r)}\right] .
$$

REMARK. Observe from (16) that $\mathbf{W} \leq 2(k-1)^{2}$, that $\max _{y} \mathbf{W}$ is a strictly increasing function of $x$, a strictly decreasing function of $y$, and that $\max _{y} \mathbf{W} \rightarrow 2(k-1)^{2}$ as $x \rightarrow \infty$. Note also, that if $r=1, \max _{y} \mathbf{W}=2(k-1)^{2}$ irrespective of the value of $x$.

It is now clear from the previous analysis that the maximum value of $\mathbf{W}$ occurs on a boundary, namely the right hand boundary for $x$. For example, when $k=2$ and $r=1 / 2$, the maximum value of $\mathbf{W}$ over the $(x, y)$ parameter space $(0,2] \times[0,2]$ occurs at $x=2, y=1 / 3$ on the right hand boundary for $x$. For a consumption tax of $15 \%$ and a profits tax of $42 \%$, the maximum value of $W$ will occur at $x=1.15$ and $y=0.87$ when $k=2$, corresponding to a consumption tax of $15 \%$ and a tariff subsidy of $13 \%$.

\section{Conclusions}

National governments have a number of policy instruments that enable them to intervene in international markets that are imperfectly competitive. In this paper, and an earlier paper [14], two such instruments, namely a specific tariff and an ad valorem consumption tax (sometimes called an ad valorem tariff) were examined. Along with Katrak and Brander and Spencer, for example, we find that under a single regime optimal welfare depends upon whether the tariff or consumption tax is in fact a tax or a subsidy, and that its value depends upon the slope of the demand curve. We also find that the optimal tariff or consumption tax depends upon the level of profits tax which 
is levied by the domestic government. For example, for an imperfectly competitive foreign industry and a profits tax less than $50 \%$ it was shown in [14] that welfare was optimized by a positive tariff, a result that is consistent with that obtained by Brander and Spencer [1] when the relative convexity of demand is zero, even though, rather surprisingly, their model did not incorporate a profits tax. The role of the profits tax in Katrak's analysis is diminished due to an error which is discussed in [14]. The dependence of optimal welfare on the profits tax and specific and ad valorem taxes, and whether they are in fact taxes or subsidies, applies irrespective of whether we optimize welfare as a function of just a tariff or just a consumption tax as in [1], [2], [8] and [14], or whether we consider welfare in the much more realistic case, as in this paper, when it is a function of both a specific tariff and an ad valorem consumption tax.

With a mix of consumption tax and tariff, we find that positive welfare is globally bounded, and that optimal welfare occurs on a boundary of the consumption tax - tariff parameter space. Furthermore, optimal welfare increases with increasing consumption tax, and decreasing tariff, possibly a subsidy, depending upon the values of parameters and the parameter space under consideration. Moreover, for a given profits tax, if the government chooses that value of consumption tax which maximizes welfare under a pure consumption tax regime, then, perhaps surprisingly, a welfare optimizing tariff will always be a subsidy. The mechanism by which this is achieved is that the loss of revenue through the tariff subsidy is offset by increases in demand, and revenue from the profits tax and consumer surplus.

Whilst this paper demonstrates that increased national welfare can flow from adopting a mix of a specific and an ad valorem tariff (consumption tax), it is not necessarily advocating this is the best strategy for governments. Although our model can achieve higher welfare, it may also be accompanied by higher total costs to the nation, a matter which is likely to have political ramifications. Tied in with these considerations are, of course, the complex international issues of tariff and protectionist policies. The matter of total costs to the nation will be considered elsewhere.

\section{References}

[1] J. Brander and B. Spencer, "Trade warfare: Tariffs and cartels", J. Int. Econ. 16 (1984) 227-242.

[2] J. Brander and B. Spencer, "Tariff protection and imperfect competition", in Monopolistic competition in international trade (ed. H. Kierzkowski), (Oxford University Press, Oxford, 1984).

[3] W. M. Corden, Trade policy and economic welfare (Oxford University Press, Oxford, 1974).

[4] P. Dasgupta and J. E. Stiglitz, "Benefit-cost analysis and trade policies", J. Pol. Econ. 82 1-33.

[5] D. De Meza, "Commercial policy towards multinational monopolies - reservations on Katrak", Ox. Econ. Pap 31 (1979) 334-337. 
[6] G. K. Helleiner, "Manufactured exports from less developed countries and multinational firms", Econ.J. 83 (1973) 21-47.

[7] T. Horst, "The theory of the multinational firm: Optimal behaviour under different tariff and tax rates", J. Pol. Econ. 79 (1971) 1059-1072.

[8] H. Katrak, "Multinational monopolies and commescial policy", Ox. Econ. Pap 29 (1977) 283-291.

[9] H. Katrak, "Multinational monopolies and commercial policy: A qualification and a reply", $O x$. Econ. Pap 31 (1979) 508-511.

[10] H. Katrak, "Multinational monopolies and monopoly regulation", Ox. Econ. Pap 32 (1980) 451466.

[11] H. Katrak, "Multinational firms' global strategies, host country indigenisation of ownership and welfare", J. Devel. Econ. 13 (1983) 331-348.

[12] H. Katrak, "Pricing policies of multinational enterprises: Host country regulation and welfare", $J$. Int. Econ. 16 (1984) 327-340.

[13] Yew-Kwang Ng, “Quasi-pareto social improvements", Am. Econ. Rev. 74 (1984) 1033-1050.

[14] J. A. Rickard, A. M. Russell and C. A. Martini, "Welfare policy and multinational monopolies", J. Austral. Math. Soc. Ser. B 34 (1992) 133-152.

[15] R. Vernon, "International investment and international trade in the product cycle", Quart. J. Econ. 80 (1966) 190-207. 